\title{
Assessment of Selected Properties of Varnish Coating of Motor Vehicles
}

\author{
Dariusz Ulbrich ${ }^{1, * \mathbb{D}}$, Jakub Kowalczyk ${ }^{1}$, Marian Jósko ${ }^{1}$, Wojciech Sawczuk ${ }^{2} \mathbb{D}$ and Przemyslaw Chudyk ${ }^{1}$ \\ 1 Institute of Machines and Motor Vehicles, Faculty of Transport and Civil Engineering, \\ Poznan University of Technology, 60-965 Poznan, Poland; jakub.kowalczyk@put.poznan.pl (J.K.); \\ marian.josko@put.poznan.pl (M.J.); przemekchudyk@gmail.com (P.C.) \\ 2 Institute of Transport, Faculty of Transport and Civil Engineering, Poznan University of Technology, \\ 60-965 Poznan, Poland; wojciech.sawczuk@put.poznan.pl \\ * Correspondence: dariusz.ulbrich@put.poznan.pl; Tel.: +61-6652248
}

Citation: Ulbrich, D.; Kowalczyk, J.; Jósko, M.; Sawczuk, W.; Chudyk, P. Assessment of Selected Properties of Varnish Coating of Motor Vehicles. Coatings 2021, 11, 1320. https:// doi.org/10.3390/coatings11111320

Academic Editors: Changheui Jang and Ingrid Milošev

Received: 9 September 2021

Accepted: 27 October 2021

Published: 29 October 202

Publisher's Note: MDPI stays neutral with regard to jurisdictional claims in published maps and institutional affiliations.

Copyright: (c) 2021 by the authors. Licensee MDPI, Basel, Switzerland. This article is an open access article distributed under the terms and conditions of the Creative Commons Attribution (CC BY) license (https:// creativecommons.org/licenses/by/ $4.0 /)$.
Abstract: The technology and methods of testing the properties of varnish coatings used in motor vehicles are constantly and successfully developed. However, in the case of automotive varnish renovation coatings used in the repair of car bodies, the problem of fitting the quality of these coatings to the quality and current condition of the coating applied to undamaged vehicle components is not definitely solved. The main goal of the research was to determine the thickness and gloss distribution of the varnish coatings. The thickness and gloss of the varnish coating on the entire body of the vehicle were measured. Classical methods of assessing these properties were used. Defects in the renovation coating were also simulated, to show their negative impact on the varnish quality. The performed tests allowed for development of a procedure and algorithm for evaluation of the quality of the car's renovation coating after the repair of the car body. The proposed procedure, expressed with the presented algorithm, allows to fit the obtained renovation coating to the quality and condition of the coating manufactured in factory on the car body in the range of its thickness up to $270 \mu \mathrm{m}$ and gloss in the range of 5-90 GU. The developed procedure for the assessment of renovation coatings can be used in workshops that repair vehicle bodies. This will allow to improve the quality of renovation coatings and bring their properties, such as thickness or gloss, closer to those applied to the vehicle's body at the factory.

Keywords: varnish coating; renovation coating; car body; varnish thickness; varnish gloss

\section{Introduction}

The varnish coating used in motor vehicles has two main functions, the protection of the vehicle body against corrosion and the decorative one that affects the visual aspect of the entire vehicle [1,2]. However, more and more people are also paying attention to the protection of the environment (environmentally friendly coating materials) and cost of painting process. Therefore, modern solutions are sought to improve both the quality of the coatings and their production process [3,4].

In the case of renovation coating, it is important to fit their condition to the coating applied to undamaged elements (coating made in factories), especially in terms of the color of the varnish coating and its gloss. It is also important to maintain a thickness similar to that of the original paint applied at the factory. Too small thickness of the renovation varnish may lead to corrosion of the car body sheet. Too high thickness of the coating may cause problems during the vehicle's operation, such as i.e., coating settling, flaking and cracking. In order to fulfill its functions, the varnish coating must be made in accordance with the technological regime of a vehicle manufacturer [1].

In industrial practice, there are no standards that define the minimum and maximum values of gloss and thickness of the varnish coating. The sparse information available in journals is only a theoretical indicator [5]. Therefore, according to the authors, it is 
important to study the thickness distribution over the entire vehicle and compare between individual values, as differences in thickness or gloss values may indicate the quality of performed car body repair.

The literatures offer a significant number of articles on the technology of applying varnish coatings e.g., [5,6], as well as current activities and technological achievements in the field of intelligent composite nano-coatings [7] and new material components [8]. These activities, in particular the hardening methods [9] and especially the UV methods [10], have improve the resistance of coatings to external mechanical factors [11], which is important in the case of automotive vehicle operations [12]. This importance is noticed by the authors of the works [13], presenting technological activities of multifunctionality of coatings. The authors also point to the importance of surface preparation for the application of coatings, especially automotive coatings [14]. Generally, technological achievements concern solutions ensuring the expected quality of coatings, including renovation varnishes [15]. Research is also conducted to develop innovative coatings with graphene that are designed to increase corrosion resistance [16]. Important from the point of view of the durability of the coatings are also: resistance to impact and cyclic deformation. Therefore, coatings that will improve these properties were developed $[17,18]$.

One of the main technological factors is to ensure the required adhesion of the varnish coating to the steel substrate $[19,20]$. Related to this, is the phenomenon of adhesion, i.e., the surface joining of layers of two different bodies that are in contact with each other due to the occurrence of intermolecular attraction [21]. The most important and most frequently listed theories of adhesion are [22,23]: mechanical theory and the theory of specific adhesion, which are related to such phenomena as, physical adsorption, chemical adsorption, diffusion, energy and electrostatic phenomena. In the case of the mechanical theory, the material is anchored primarily on macro-inequalities, as well as on micro and sub-micro-inequalities of the surface, which results in obtaining the appropriate strength of the connection. The physicochemical theory of adhesion based on the phenomena of physical and chemical adsorption specifies the occurrence of intermolecular interactions in the form of Van der Waals forces. Another of the specific theories-diffusion, discusses the phenomenon of diffusion of particles of two connected materials that are in direct contact. The phenomenon of tacking, or joining by hooking, is the basis of the energetic theory of adhesion. In addition to the phenomenon of adhesion, the cohesion phenomenon, i.e., the mutual attraction of particles as a result of the cohesion forces (intermolecular), is important in the case of joints between the coating and the substrate [22].

Specific solutions for the quality control of coatings are also proposed, ensuring the necessary tolerance of accuracy and enabling the assessment of the structure and properties of coatings [24].

In terms of assessing the properties of varnish coatings, hyperspectral [25], spectrophotometric [26] and thermovision techniques are proposed [27]. Traditional nondestructive thickness control methods [28], including the eddy current method [29], are also useful. Great attention is paid to detecting defects in coatings [30], monitoring the color of automotive lacquer [31], assessing the natural photoaging of the coatings [32] and external dynamic damage to the paint, using reliable non-destructive methods [33]. Nevertheless, in terms of assessing the properties of varnish coatings, mainly non-destructive and destructive methods, often adopted for car paints, are used.

Khasanov et al. [34] presented main factors influencing the quality of paint and varnish coating when repairing the car body. The main important factors from point of view of the quality of renovation coating were i.e., pollution of compressed air and varnishes, paints and varnishes application on badly prepared surface as well as the use of inappropriate paints and varnishes or the solvent. Suleimanov et al. [35] compared the properties of coatings applied in the factory and renovation coatings produced during the car body repair stage. He stated that by maintaining the technological regime, it is possible to produce varnish renovation coatings of a quality similar to those applied in the factory. Therefore, it is important to recreate the thickness of the coatings at the stage of car body 
repair, as it was produced in the factory. In available publications [5,36], the thickness of the factory applied coating is in the range of $90-140 \mu \mathrm{m}$. The color of the varnish coating was investigated by Gomez et al. [37] and the evaluation between visual inspection and instrumental inspection was performed. The main conclusion from this test was that the observer accepted a larger number of color pairs at the stage of color assessment and selection than the tolerance demanded by the manufacturer. There is no clear procedure in the literature for the inspection of a car renovation coating, taking into account the current state of the factory coating, expressed by its most important properties. It is important to fit the properties of the renovation coating to the current condition of the car's varnish coating and ensure its desired quality (without typical paint defects).

The main goal of the research presented in the article was to determine the thickness and gloss distribution of the varnish coatings of newly produced motor vehicles, both passenger cars and delivery vans. The uniform distribution of the thickness of the varnish coating is important both from the visual point of view and from the point of view of protecting the car body sheet against corrosion. Moreover, the determination of the gloss distribution on the varnish allows to evaluate the quality of the coating, which is important for the ever-increasing requirements of customers of automotive manufacturers. An additional aim of the article was to determine the influence of selected defects on the properties of the varnish coating, such as thickness, gloss, adhesion and hardness. The defects were selected based on the experience of the authors of the article and created artificially as a result of changes in the parameters of the painting process. The performed tests allowed for the assessment of selected properties of both factory and renovation coatings, which are produced during the repair of car bodies. The final effect of the works presented in this article is developed procedure for assessing the quality of the renovation coating, which may be used at the quality control stage of the renovation coatings in varnish renovation car workshops. The novelty presented in the article is the determination of the thickness and gloss distribution of varnish coatings and the development, based on this measurement results, the quality control guidelines for renovation coatings produced in paint shops.

\section{Materials and Methods}

\subsection{Samples}

\subsubsection{New Car Body}

In the case of new motor vehicles, two types of vehicles were selected: a B-segment city car with two-layer metallized varnish and a delivery vehicle with acrylic white coating. Vehicles from segment $B$ had the same color of coating on the entire vehicle, except for the roof, which was painted in other (black), also metallic color. The vehicles were brand new, not registered. The thickness and gloss tests were carried out in one of the car showrooms in Poland. On the other hand, delivery vehicles were tested in the manufacturing hall after the quality test. In both cases, 10 vehicles, identical in terms of varnish coating were selected from both the showroom and the factory. Additionally, for B-segment vehicles, before the measurements, the lacquer coating was washed in order to remove dirt resulting from the process of transporting vehicles from the factory to the car showroom. The lacquer coating of the tested cars was applied in accordance with the technology used in modern factories producing motor vehicles. Waterborne varnishes were used for both types of vehicles. The first coating applied to the steel body was an electro coating protecting against corrosion. It was applied by the immersion method in tanks. Subsequently, the primer, basecoat and clearcoat were applied and the car body was heated in an oven $[1,5]$.

\subsubsection{Renovation Varnish Coating}

The samples for renovation process were cut from the sliding door of a delivery vehicle produced in 2011. Due to the known, accident-free history of the vehicle, the body parts had the manufacturer's original anti-corrosion protection in the form of a galvanized zinc coating. The lacquer coating was removed from the sheet by the chemical method. It was 
important, not to damage the factory zinc coating. Figure 1 shows steel samples prepared for renovation process (after the old varnish layer was removed).

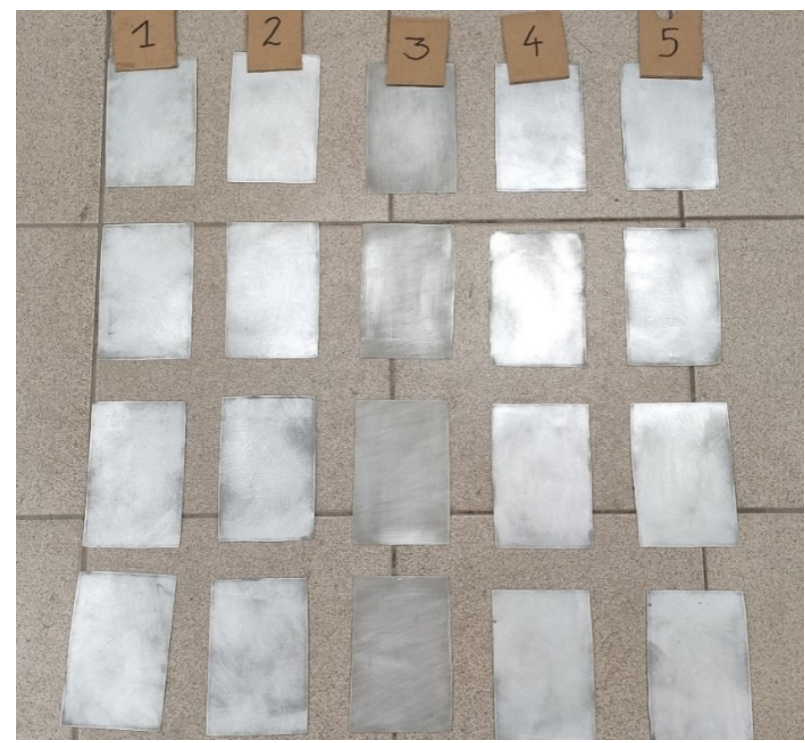

Figure 1. Steel samples after removing varnish coating.

The sample size is approximately $95 \times 145 \mathrm{~mm}$. Samples were divided into five series (four samples in each), which are characterized by errors made during surface preparation as well as resulting from non-compliance with the manufacturer's recommendations of the varnish products and poor conditions during the application of the varnish. The individual stages of painting the samples were performed on the same day to ensure the same parameters of temperature and humidity of the environment. The individual series of samples can be characterized as follows:

- Series 1-master sample made in accordance with the recommendations of the varnish coating manufacturer;

- Series 2-too long time between base coating and clear varnish application;

- Series 3-none grinding surface of the sample;

- Series 4-clear varnish with too low hardener;

- Series 5-contamination of samples during the application of the varnish coating.

Series 1 was produced based on the recommendations of the manufacturer of varnish products and the knowledge supported by both specialist literature and the experience of the authors. Before applying the primer, the surface of the samples was carefully sanded with an eccentric grinder and P240 paper. Then, it was degreased with the APP W900 (APP, Wrzesnia, Poland) universal cleaner with the use of two cleaning rags. The acrylic primer, prepared in the proportions $4: 1$ with the hardener and with $20 \%$ addition of acrylic reducer was applied to the prepared surface with an Airless spray gun. After $48 \mathrm{~h}$ from the application of the last layer of primer, the surface of the sample was prepared for the painting. For this purpose, a grinder together with P400 paper was used. The surface of the sample was cleaned of dust and grease with a cleaner. The base coat was prepared (in accordance to the manufacturer's recommendations) in a 2:1 ratio with an acrylic reducer. Three layers of basecoat were applied. The first, the thinnest, of a contact character, and the two covering ones. After the last covering layer was applied, the spray gun was cleaned of the remains of the base coat and (in accordance with the manufacturer's instructions) after $15 \mathrm{~min}$, a two-layer clear coat was applied.

Series 2 was produced using an excessively long time between the application of the base coating and clear varnish. This situation may take place in a paint shop when the pneumatic system or the spray gun itself breaks down, or when the painter is forced to take a longer break due to random events. For the second series, the application time between 
coats was increased from the recommended $15 \mathrm{~min}$ to $12 \mathrm{~h}$. The remaining parameters and the procedure were identical to those for the production of samples from the first series.

Series 3 contains incorrect grinding processes prior to the application of the primer. The substrate was cursorily grinded with the APP non-woven fabric abrasive. The operation of grinding the substrate with P240 paper was not included in renovation process. The subsequent stages of applying the base and clear varnishes were carried out analogically to the samples of the first series.

The 4 th series of samples contains the wrong ratio of hardener to clear varnish (a trace amount of hardener was used). This error may be caused by the lack of accessories supporting the precise formation of the mixture of varnish and hardener. For this reason, for the purposes of the study, a clear varnish was first prepared in the amount of $100 \mathrm{~mL}$ with a trace amount of hardener dispensed as three drops $(3 / 10 \mathrm{~mL})$ for the entire volume of the varnish. The samples were painted using the same technique and maintaining the same abrasives as for the series 1 samples.

The series of samples marked with the number five was prepared in a similar way to the first series, but during painting with clear varnish, dust and mist containing grease got into the environment. The dusting was simulated by grinding the polyester putty on the stand in the area of preparation for painting, which happens in practice. On the other hand, the greasy mist was created as a result of shining plastic elements in the engine compartment. The polishing process is carried out after both varnish and mechanical repair in order to restore the required level of cleanliness of the surface. During painting in workshop conditions, additional work at workstations adjacent to the painting station and aerosol lubricants should be avoided throughout the building in order to prevent the resulting defects.

The selected sample from the fifth series, characterized by defects is shown in Figure 2. On the surface of the samples from the fifth series, numerous craters were formed. Additionally, some inclusions in the form of dust and even larger particles of polyester putty trapped in the varnish structure were observed. Most of the inclusions were removed with P2000 paper and polishing paste, leaving only slight traces in the varnish structure. On the other hand, the craters and pores formed as a result of greasing in the painting zone are so deep that only re-painting is able to remove the defects.

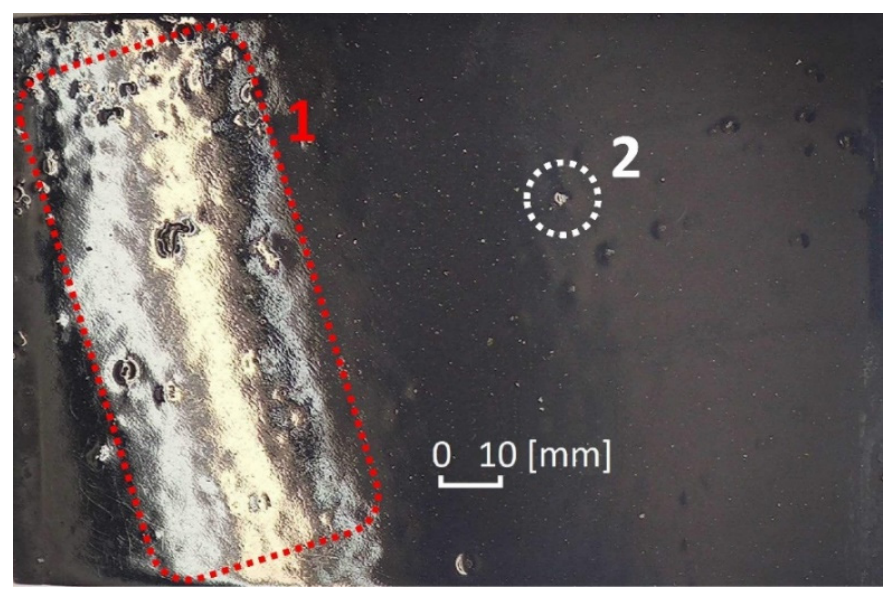

Figure 2. A sample with artificially produced defects; 1 -an area with damaged clear coat and 2-flake of the varnish coating.

\subsection{Coating Thickness Testing}

The study of the thickness distribution of the varnish coating for both the body of the new vehicle and the samples was carried out using the PC-Leptoscope with a 2050.111 probe for ferromagnetic substrates, manufactured by Karl Deutsch (Wuppertal, Germany). This device uses the phenomenon of magnetic induction. The single-pole, flat probe Karl Deutsch 2050.111 (Wuppertal, Germany) in conjunction with the STATWIN 2002 software 
version 1.1 enables precise coating thickness measurements with a resolution of $0.1 \mu \mathrm{m}$ in the range of 0-3000 $\mu \mathrm{m}$. The manufacturer states the accuracy of the measurement at the level of $3 \% \pm 1 \mu \mathrm{m}$ for coatings above $100 \mu \mathrm{m}$ [38]. For new vehicles, on each element, i.e., left front door, roof, etc., measurement points were established and are presented in Figure 3. In each point, 10 thickness measurements were taken. In total, the thickness of the varnish coating was measured 420 times on each new car body. In the case of the samples of renovation coatings, 60 measurements were made, assuming 6 measurement points, and 10 measurements were made in each of them (determined on the basis of previous statistical analysis).

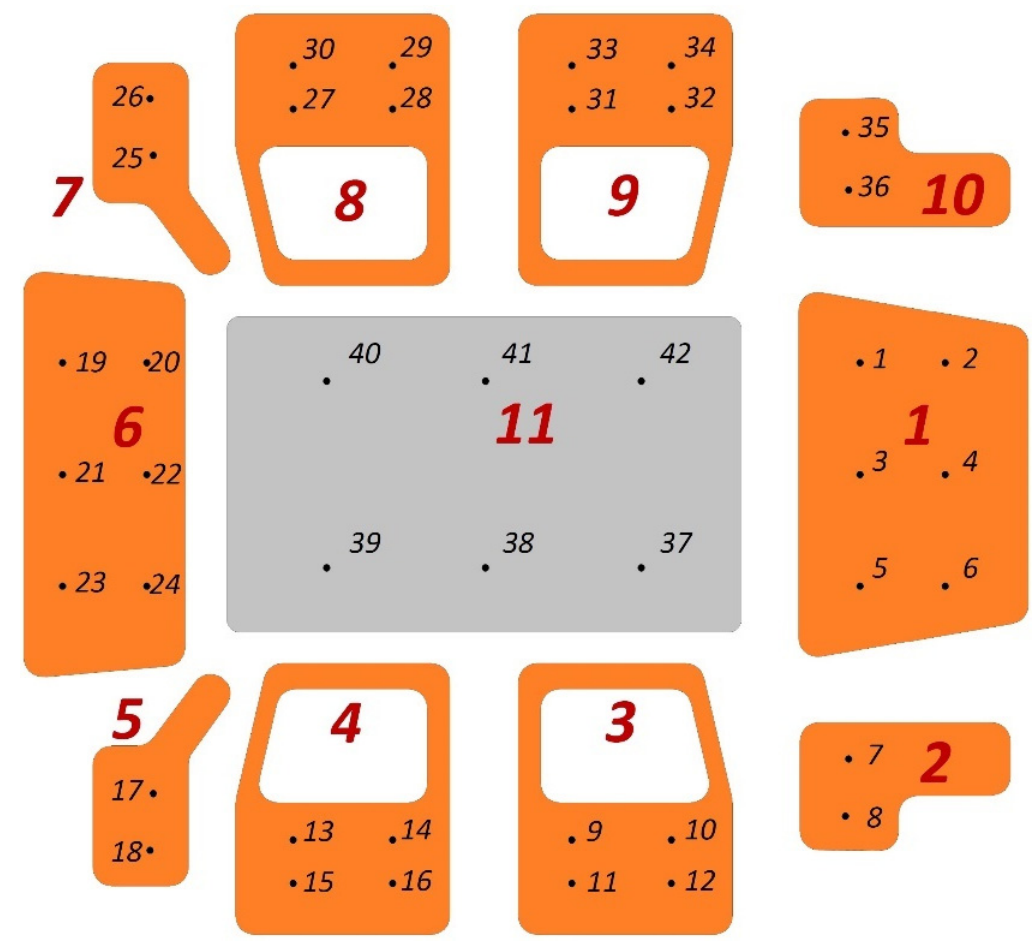

Figure 3. Measurement point distribution on a car body; the number of elements was marked by red color.

\subsection{Coating Gloss Test}

Gloss can be a measure of the quality of a varnish coating on a car body. It is a visual impression related to the brightness of the direct light reflected by the surface. The gloss test was carried out using an Elcometer 480, Model T gloss meter (Manchester, UK). The device measures at an angle of $60^{\circ}, 20^{\circ} / 60^{\circ}$ or $20^{\circ} / 60^{\circ} / 85^{\circ}$, and allows to generate a report on the device screen. In addition, the device allows to determine the haze parameter, helpful in the selection of samples showing a significant difference in gloss and the maximum and minimum gloss values. For a gloss value greater than $70 \mathrm{GU}$ and a test geometry of $60^{\circ}$, the gloss value for all samples should be read at the $20^{\circ}$ angle measurement. For new vehicles, a series of measurements on each of them was conducted. There are selected (similarly to the measurements of the varnish thickness) 42 measurement points, which make up 11 areas (individual body elements). Ten measurements were executed at each point. For each of the restoration varnish samples, 10 measurements of gloss parameters were carried out.

\subsection{Renovation Coating Adhesion Test}

The cross-cut adhesion test was carried out using a single-blade knife $0.4 \mathrm{~mm}$ thick, a $3 \mathrm{~mm}$ cut template, incised with a laser method, and an AN1539M0025 adhesive tape. The tape used for adhesion testing has a declaration of compliance with the PN-EN ISO 2409 standard [39] and adhesion to steel of $4.4 \mathrm{~N} / \mathrm{cm}$, thickness $43 \mu \mathrm{m}$ and tensile strength 
$37 \mathrm{~N} / \mathrm{cm}$. Adhesive tape $25 \mathrm{~mm}$ width was produced in week 1 of 2021 . The test was performed at two representative locations on the surface of each sample. The tape was torn off as per standard once in each direction of the score line. Adhesion is assessed in a six-point grading, where 0 corresponds to very good adhesion without any detachment, and 5 occurs when detachment are above $65 \%$ of the cross-cut area. Coating adhesion tests were performed only on samples of the renovation varnish.

\subsection{Renovation Coating Hardness Test}

The pencil-hardness test was carried out in accordance with the conditions described in the standard, such as: the angle $\left(45^{\circ}\right)$ between the pencil tip and the tested surface, the cylindrical shape of the pencil's graphite tip and the constant pressure exerted by the pencil on the tested coating of $750 \pm 10 \mathrm{~g}$. The pencil tester made for the purpose of the study, shown in Figure 4, meets the conditions described in the PN-EN ISO 15184 standard [40]. According to this standard, pencil hardness can be defined as the coating's resistance to damage caused by moving the pencil tip of a given hardness along the tested surface. The device presses the tip of the pencil onto the coating. Then the device is moved (that's why the wheels are mounted-it is a kind of trolley), and the tip with a pencil affects the coating. If the pencil does not show any damage to the coating, another one that is harder is used. The hardest pencil that will not leave any damage on the surface of the test sample is considered its hardness. Damage may take the form of visible or perceptible plastic deformations, cohesive cracks or their connections. The hardness test was carried out in the lower area of each of the samples, and the results were determined on the basis of an organoleptic assessment of the coating damage.

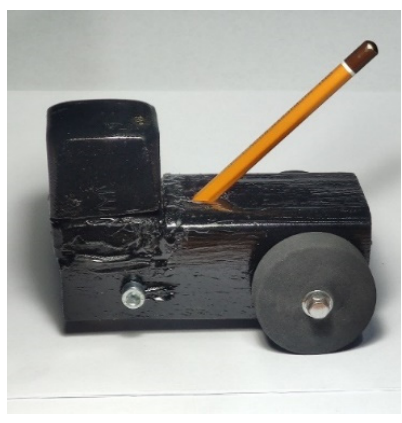

(a)

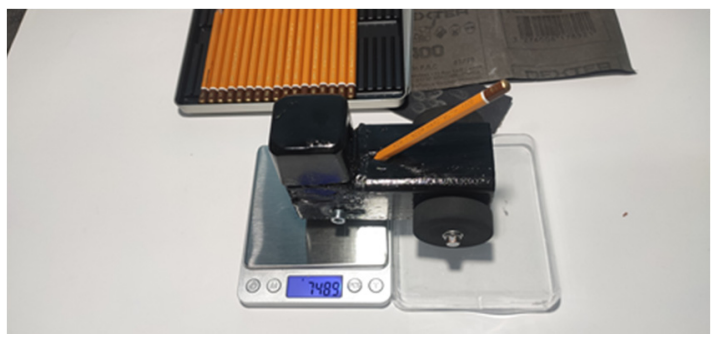

(c)

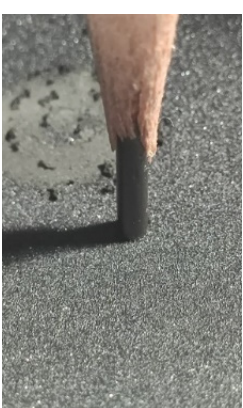

(b)

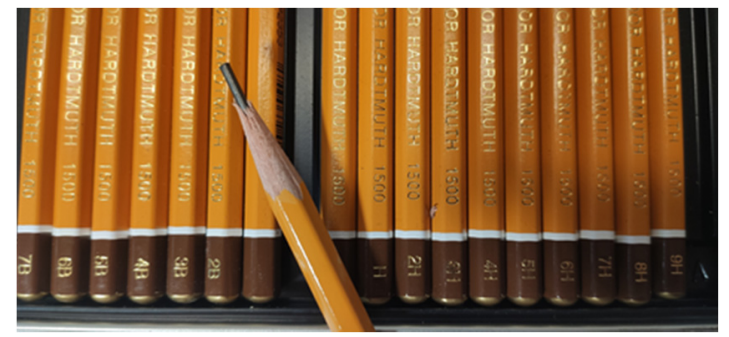

(d)

Figure 4. The set for testing the hardness of coatings using the pencil method; (a) tester with pencil, (b) pencil prepared for examination according to the standard, (c) device weight measurement and (d) view of pencils of different hardness used in the research.

\section{Results}

\subsection{Results of Varnish Coating Thickness Distribution on the Body of New Vehicles}

The test was carried out on ten brand new vehicles-before these vehicles leave the factory and on ten new vehicles prepared for sale at an authorized showroom. The measurement results for the B segment vehicle are summarized in Table 1 and for the delivery vehicle in Table 2. 
Table 1. The results of the measurements of the coating thickness on the vehicle from segment $\mathrm{B}$.

\begin{tabular}{|c|c|c|c|c|c|c|c|}
\hline Measurement Place * & $\begin{array}{l}\text { Mean Value } \\
(\mu \mathrm{m})\end{array}$ & $\begin{array}{c}\text { Standard } \\
\text { Deviation } \\
(\mu \mathrm{m})\end{array}$ & $\begin{array}{l}\text { Min Value } \\
(\mu \mathrm{m})\end{array}$ & $\begin{array}{c}\text { Max Value } \\
(\mu \mathrm{m})\end{array}$ & $\begin{array}{l}\text { Median } \\
(\mu \mathrm{m})\end{array}$ & $\begin{array}{l}\text { First Quantile } \\
\qquad(\mu \mathrm{m})\end{array}$ & $\begin{array}{c}\text { Third } \\
\text { Quantile } \\
(\mu \mathrm{m})\end{array}$ \\
\hline Engine hood (1) & 120.60 & 2.8 & 117 & 126 & 120.50 & 118.50 & 121.75 \\
\hline Front right fender (2) & 122.30 & 3.3 & 118 & 128 & 123.00 & 119.50 & 123.00 \\
\hline Front Right door (3) & 121.10 & 1.6 & 119 & 123 & 121.50 & 119.25 & 122.75 \\
\hline Rear right door (4) & 116.00 & 2.8 & 112 & 119 & 116.00 & 114.00 & 119.00 \\
\hline Rear right fender (5) & 118.50 & 2.2 & 115 & 122 & 119.00 & 117.25 & 119.75 \\
\hline Boot lid (6) & 121.00 & 3.4 & 116 & 126 & 120.00 & 118.25 & 124.25 \\
\hline Rear left fender (7) & 123.10 & 2.9 & 119 & 128 & 123.00 & 121.25 & 124.75 \\
\hline Rear left door (8) & 120.70 & 2.0 & 118 & 124 & 120.50 & 120.00 & 121.00 \\
\hline Front left door (9) & 115.40 & 2.9 & 111 & 120 & 115.00 & 113.25 & 117.75 \\
\hline Front left fender (10) & 119.30 & 3.0 & 115 & 124 & 118.50 & 118.00 & 121.75 \\
\hline Roof (11) & 191.60 & 4.5 & 186 & 198 & 190.50 & 187.25 & 195.75 \\
\hline
\end{tabular}

* number of parts in accordance with Figure 3-applies to all markings.

Table 2. The results of the measurements of the coating thickness of the delivery vehicle.

\begin{tabular}{|c|c|c|c|c|c|c|c|}
\hline Measurement Place & $\begin{array}{l}\text { Mean Value } \\
(\mu \mathrm{m})\end{array}$ & $\begin{array}{c}\text { Standard } \\
\text { Deviation } \\
(\mu \mathrm{m})\end{array}$ & $\begin{array}{c}\text { Min Value } \\
(\mu \mathrm{m})\end{array}$ & $\begin{array}{c}\text { Max Value } \\
(\mu \mathrm{m})\end{array}$ & $\begin{array}{l}\text { Median } \\
(\mu \mathrm{m})\end{array}$ & $\begin{array}{l}\text { First Quantile } \\
\qquad(\mu \mathrm{m})\end{array}$ & $\begin{array}{c}\text { Third } \\
\text { Quantile } \\
(\mu \mathrm{m})\end{array}$ \\
\hline Engine hood (1) & 125.80 & 8.9 & 109 & 134 & 129.50 & 124.50 & 131.50 \\
\hline Front right fender (2) & 129.10 & 10.3 & 112 & 143 & 130.00 & 121.00 & 138.00 \\
\hline Front Right door (3) & 129.40 & 10.3 & 109 & 138 & 134.00 & 128.25 & 137.25 \\
\hline Rear right door (4) & 132.10 & 10.8 & 111 & 142 & 136.50 & 134.25 & 138.00 \\
\hline Rear right fender (5) & 123.60 & 8.8 & 103 & 132 & 126.50 & 124.25 & 128.75 \\
\hline Boot lid (6) & 109.70 & 5.4 & 99 & 117 & 110.50 & 107.25 & 113.00 \\
\hline Rear left fender (7) & 122.80 & 10.0 & 102 & 134 & 127.00 & 119.50 & 127.00 \\
\hline Rear left door (8) & 129.80 & 10.0 & 111 & 140 & 134.00 & 126.25 & 136.50 \\
\hline Front left door (9) & 127.40 & 7.0 & 112 & 134 & 129.50 & 128.25 & 132.25 \\
\hline Front left fender (10) & 119.10 & 9.2 & 101 & 127 & 122.50 & 118.25 & 125.00 \\
\hline Roof (11) & 117.50 & 9.1 & 104 & 131 & 114.00 & 111.00 & 127.00 \\
\hline
\end{tabular}

\subsection{Results of Varnish Coating Gloss Distribution on the Body of New Vehicles}

According to the manufacturer of the Elcometer 480 gloss meter, Model T (Manchester, $\mathrm{UK}$ ), the reproducibility of results with a measuring range from 10 to $100 \mathrm{GU}$ is $0.5 \mathrm{GU}$. In the first stage, a test was carried out on three brand new vehicles, which were delivered to one of the points of the authorized dealer network and were intended for sale. The tests carried out on three vehicles allowed for the assumption that, in accordance with PN-EN ISO 2813:2014-11 [41], subsequent tests will be carried out for the light incidence angle of $20^{\circ}$. The measurements for the angles of $60^{\circ}$ and $85^{\circ}$ were rejected because the tested surfaces had a high gloss (over $70 \mathrm{GU}$ when measured at $60^{\circ}$ ), and the angle of $20^{\circ}$ is used for this range. The summary of the results for the B-segment vehicles is presented in Table 3, and for the delivery vehicle is presented in Table 4 . Both tables contain the results of gloss measurements at a test angle of $20^{\circ}$.

Table 3. The results of the measurements of the coating gloss $\left(20^{\circ}\right)$ of the segment B car.

\begin{tabular}{|c|c|c|c|c|c|c|c|}
\hline Measurement Place & $\begin{array}{l}\text { Mean Value } \\
\text { (GU) }\end{array}$ & $\begin{array}{c}\text { Standard } \\
\text { Deviation } \\
\text { (GU) }\end{array}$ & $\begin{array}{l}\text { Min Value } \\
\text { (GU) }\end{array}$ & $\begin{array}{c}\text { Max Value } \\
\text { (GU) }\end{array}$ & $\begin{array}{l}\text { Median } \\
\text { (GU) }\end{array}$ & $\begin{array}{l}\text { First Quantile } \\
\text { (GU) }\end{array}$ & $\begin{array}{c}\text { Third } \\
\text { Quantile } \\
\text { (GU) }\end{array}$ \\
\hline Engine hood (1) & 73.10 & 7.0 & 63 & 83 & 74.00 & 66.75 & 78.50 \\
\hline Front right fender (2) & 71.60 & 3.4 & 63 & 75 & 73.00 & 70.00 & 74.00 \\
\hline Front Right door (3) & 66.40 & 4.1 & 60 & 72 & 68.00 & 62.50 & 69.00 \\
\hline Rear right door (4) & 58.80 & 4.4 & 54 & 67 & 57.00 & 55.00 & 62.25 \\
\hline Rear right fender (5) & 65.40 & 8.2 & 50 & 84 & 66.00 & 60.75 & 67.75 \\
\hline Boot lid (6) & 57.40 & 6.4 & 50 & 66 & 56.50 & 51.25 & 64.50 \\
\hline Rear left fender (7) & 66.60 & 2.4 & 64 & 72 & 67.00 & 64.25 & 67.75 \\
\hline Rear left door (8) & 59.50 & 7.9 & 46 & 69 & 64.00 & 53.50 & 64.75 \\
\hline Front left door (9) & 70.60 & 5.7 & 62 & 78 & 70.00 & 66.25 & 76.00 \\
\hline Front left fender (10) & 70.60 & 6.3 & 58 & 82 & 71.50 & 67.25 & 74.25 \\
\hline Roof $(11)$ & 73.20 & 5.7 & 65 & 82 & 73.00 & 68.25 & 78.00 \\
\hline
\end{tabular}


Table 4. The results of the measurements of the coating gloss $\left(20^{\circ}\right)$ of the delivery vehicle.

\begin{tabular}{|c|c|c|c|c|c|c|c|}
\hline Measurement Place & $\begin{array}{l}\text { Mean Value } \\
\text { (GU) }\end{array}$ & $\begin{array}{c}\text { Standard } \\
\text { Deviation } \\
\text { (GU) }\end{array}$ & $\begin{array}{l}\text { Min Value } \\
\text { (GU) }\end{array}$ & $\begin{array}{l}\text { Max Value } \\
\text { (GU) }\end{array}$ & $\begin{array}{l}\text { Median } \\
\text { (GU) }\end{array}$ & $\begin{array}{l}\text { First Quantile } \\
\text { (GU) }\end{array}$ & $\begin{array}{c}\text { Third } \\
\text { Quantile } \\
\text { (GU) }\end{array}$ \\
\hline Engine hood (1) & 88.70 & 0.5 & 88 & 89 & 89.00 & 88.25 & 89.00 \\
\hline Front right fender (2) & 88.80 & 0.6 & 88 & 90 & 89.00 & 88.25 & 89.00 \\
\hline Front Right door (3) & 88.70 & 0.5 & 88 & 89 & 89.00 & 88.25 & 89.00 \\
\hline Rear right door (4) & 88.90 & 0.5 & 88 & 90 & 89.00 & 89.00 & 89.00 \\
\hline Rear right fender (5) & 88.50 & 0.5 & 88 & 89 & 88.50 & 88.00 & 89.00 \\
\hline Boot lid (6) & 88.80 & 0.6 & 88 & 90 & 89.00 & 88.25 & 89.00 \\
\hline Rear left fender (7) & 88.80 & 0.4 & 88 & 89 & 89.00 & 89.00 & 89.00 \\
\hline Rear left door (8) & 89.00 & 0.0 & 89 & 89 & 89.00 & 89.00 & 89.00 \\
\hline Front left door (9) & 88.70 & 0.5 & 88 & 89 & 89.00 & 88.25 & 89.00 \\
\hline Front left fender (10) & 88.70 & 0.9 & 87 & 90 & 89.00 & 88.00 & 89.00 \\
\hline Roof (11) & 88.70 & 0.5 & 88 & 89 & 89.00 & 88.25 & 89.00 \\
\hline
\end{tabular}

\subsection{Results of the Properties Investigations of Renovation Varnish Coating}

In the first stage of research on renovation coatings, the varnish thickness was measured at 6 measuring points. The results of these measurements are summarized in Table 5.

Table 5. The results of the measurements of the coating average thickness for samples in $\mu \mathrm{m}$.

\begin{tabular}{cccccc}
\hline \multirow{2}{*}{$\begin{array}{c}\text { Measurement } \\
\text { Area }\end{array}$} & Sample 1 & Sample 2 & Sample 3 & Sample 4 & Sample 5 \\
\cline { 2 - 5 } & 130 & 120 & 131 & 240 & 105 \\
1 & 129 & 156 & 127 & 239 & 102 \\
2 & 145 & 138 & 136 & 199 & 101 \\
3 & 138 & 112 & 142 & 265 & 80 \\
5 & 137 & 118 & 137 & 254 & 102 \\
6 & 138 & 163 & 141 & 270 & 82 \\
Mean Value & 137 & 134 & 134 & 238 & 97 \\
Standard Deviation & 6 & 18 & 6 & 27 & 10 \\
\hline
\end{tabular}

The average thickness of most renovation coatings is approximately $134 \mu \mathrm{m}$. This value is in line with the customary standard for the thickness of automotive varnish. However, this is a conventional term, because the reference thickness of renovation varnish coatings is not determined by any standard. The increased thickness of the coating on the samples in series 4 is due to the increased density of the clear varnish as it was applied without the addition of a reducer. A large decrease in the thickness of the varnish coating after the polishing process of the samples from the series 5 is caused by the deleterious process of removing inclusions and craters.

In the second stage of the renovation varnish test, the gloss test was performed. The results of the gloss values for the incidence angle of $20^{\circ}$ for individual samples are summarized in Table 6 . The gloss values are consistent with the visual observation. In the case of samples from series 5, the measuring device signaled a measurement error. It may indicate a significant reduction of the gloss of the varnish due to defects in the coating and the impossibility of perform reliable measurements.

In the next stage of the experiment, the samples with the renovation coating were tested for adhesion using the cross-cut method. Sample 3, the surface of which was prepared by WS 222 (APP, Wrzesnia, Poland) non-woven fabric abrasive, was the only one to show very good adhesion between the coating and the substrate. The adhesion of the coating in this sample is classified as 5 in the adhesion rating scale according to the standard. The remaining samples were prepared with P240 paper, in accordance with the recommendations of the base coating manufacturer. In the case of samples 1,2, 4 and 5, there was an adhesive fracture of $90 \%-100 \%$ of the surface of the incision grid. The tests were performed twice, maintaining the repeatability of the results. The poor adhesion of the renovation coating to the substrate was caused both by changes in the technological 
process of lacquer preparation, as well as by insufficient mechanical adhesion. The coating fragments did not anchor in the micro-inequalities of the surface, which resulted in low adhesion and detachment of practically the entire tested area of the coating. Changing the proportions of the individual components of the renovation varnish coating could also affect the phenomenon of specific adhesion, which is just as important as mechanical adhesion. Values of the Van der Waals forces which are too low decrease the adhesion of the coating to the substrate. The method of testing the adhesion of the coating to the substrate used in the research is a simple and effective method, but it cannot be used at the stage of assessing the quality of the paint coating after the repair process. To assess the adhesion of coatings to the substrate, the ultrasonic method can be used, which has so far been used to assess the adhesion of the putty adhesive coatings applied to the car body sheet [42]. The results of the adhesion test are shown in Figure 5.

Table 6. The results of the measurements of the coating average gloss.

\begin{tabular}{cccccc}
\hline \multirow{2}{*}{$\begin{array}{c}\text { Measurement } \\
\text { Area }\end{array}$} & Samples & \multicolumn{5}{c}{ Sample 2 } & Sample 3 & Sample 4 & Sample 5 \\
\cline { 2 - 6 } & Sample & Sample & 76.1 & 21.1 & - \\
2 & 79.7 & 78.6 & 75.8 & 29.7 & - \\
3 & 79.6 & 78.2 & 77.7 & 29.1 & - \\
4 & 79.6 & 78.4 & 76.0 & 29.3 & - \\
5 & 79.7 & 78.3 & 76.0 & 29.5 & - \\
6 & 79.7 & 78.4 & 76.8 & 29.7 & - \\
Standard Deviation & 79.6 & 78.2 & 76.4 & 29.1 & - \\
\hline
\end{tabular}

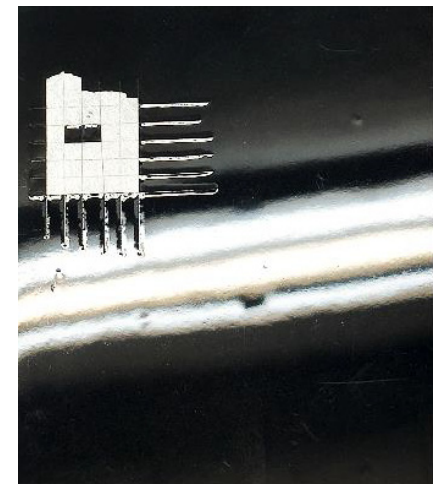

(a)

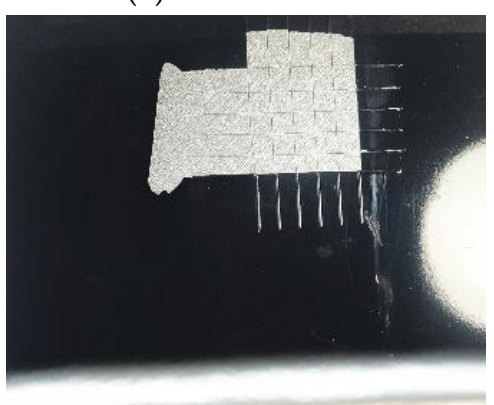

(d)

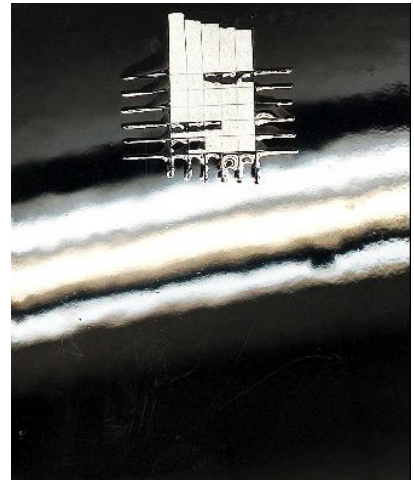

(b)

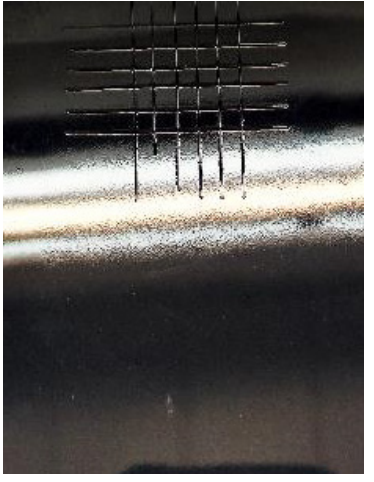

(c)

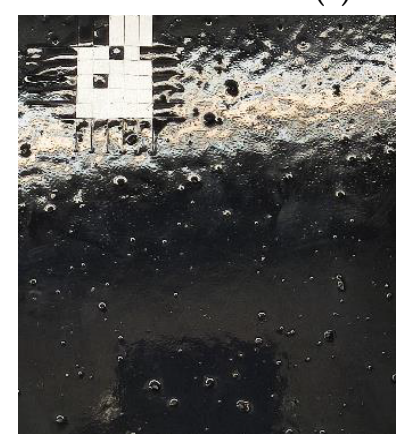

(e)

Figure 5. Results of lacquer adhesion tests using the cross-cut method; (a) series 1, (b) series 2, (c) series 3, (d) series 4 and (e) series 5 .

In the last stage of the research, the hardness of the coatings was assessed. The hardness test was carried out in the free area of each sample. The results were determined on the basis of the organoleptic assessment of the caused damage. Samples 1, 2, 3 and 
5 have a similar hardness of coating. Sample 4, with a smaller amount of hardener, has a much lower hardness. Differences can also be noticed in the resistance of the varnish coatings to adhesive or cohesive cracking. For sample 3, no cracks occurred. Sample number 5 has the lowest fracture toughness. The test results in the form of photos are shown in Figure 6, and Table 7 summarizes the most important results.

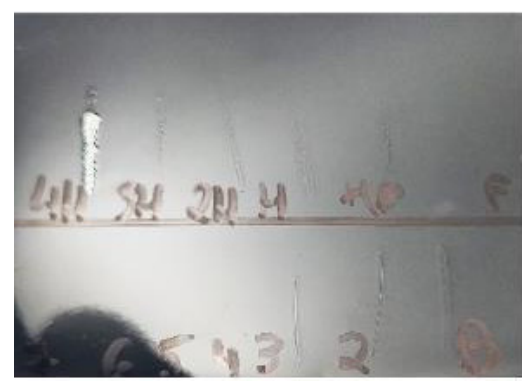

(a)

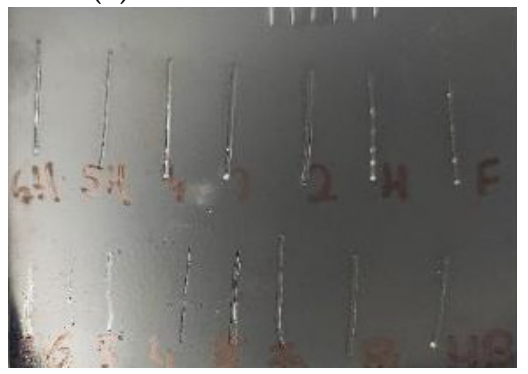

(d)

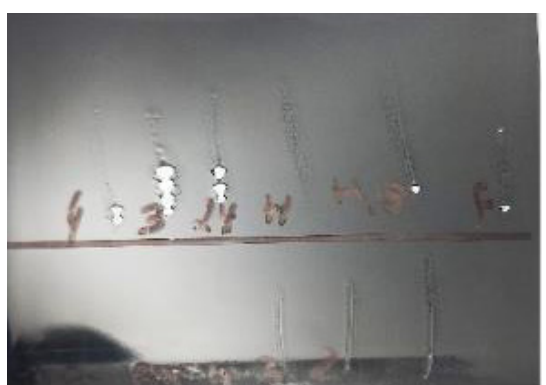

(b)

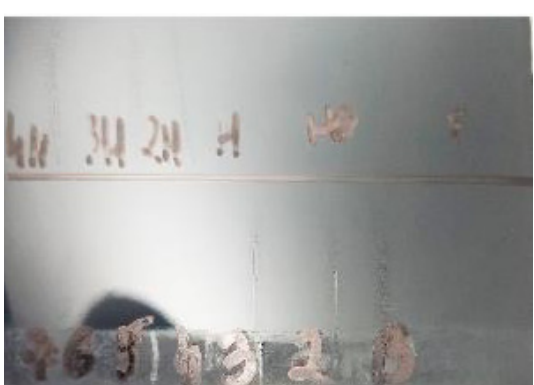

(c)

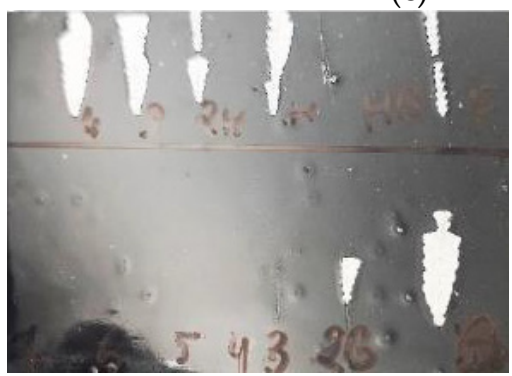

(e)

Figure 6. Results of lacquer hardness tests; (a) series 1, (b) series 2, (c) series 3, (d) series 4 and (e) series 5.

Table 7. Pencil-hardness for individual samples.

\begin{tabular}{lccccc}
\hline Type of Damage & Sample 1 & Sample 2 & Sample 3 & Sample 4 & Sample 5 \\
\hline Pencil Hardness & $4 \mathrm{~B}$ & $4 \mathrm{~B}$ & $4 \mathrm{~B}$ & $8 \mathrm{~B}$ & $4 \mathrm{~B}$ \\
Adhesive Crack & $4 \mathrm{H}$ & $2 \mathrm{H}$ & - & - & $2 \mathrm{~B}$ \\
Cohesive Crack & - & - & - & HB & - \\
\hline
\end{tabular}

\section{Discussion}

During the study of new vehicles, 11 areas of the car body of motor vehicles were analyzed. In the case of the B segment vehicle, a much thicker layer of paint coating, compared to the delivery vehicle, was on the roof. The difference is around $75 \mu \mathrm{m}$ and is caused by the additional paintwork (the color of the roof differed from the colors of the rest of the body). In most cases, the coating thickness did not differ by more than 10 percent. A delivery vehicle was characterized by a lower value of the coating thickness of the varnish layer only on the door of the luggage compartment, where the average thickness of the layer was $110 \mu \mathrm{m}$. In the B-segment vehicle, the average coating thickness on the doors was $121 \mu \mathrm{m}$.

A similar trend can be observed for the minimum and maximum values of the varnish thickness. The minimum and maximum thickness of the varnish layer on the roof of segment B vehicle is equal 186 and $198 \mu \mathrm{m}$. In the case of a delivery vehicle, these values are equal 104 and $131 \mu \mathrm{m}$. The lowest thickness of the varnish layer $(99 \mu \mathrm{m})$ was found on the door of the cargo space of the delivery vehicle. The largest (excluding the B-segment car roof) was located on the fender of the delivery vehicle. The differences in the average thickness of the varnish coating for the two selected elements (for all vehicles) are shown in Figures 7 and 8. 


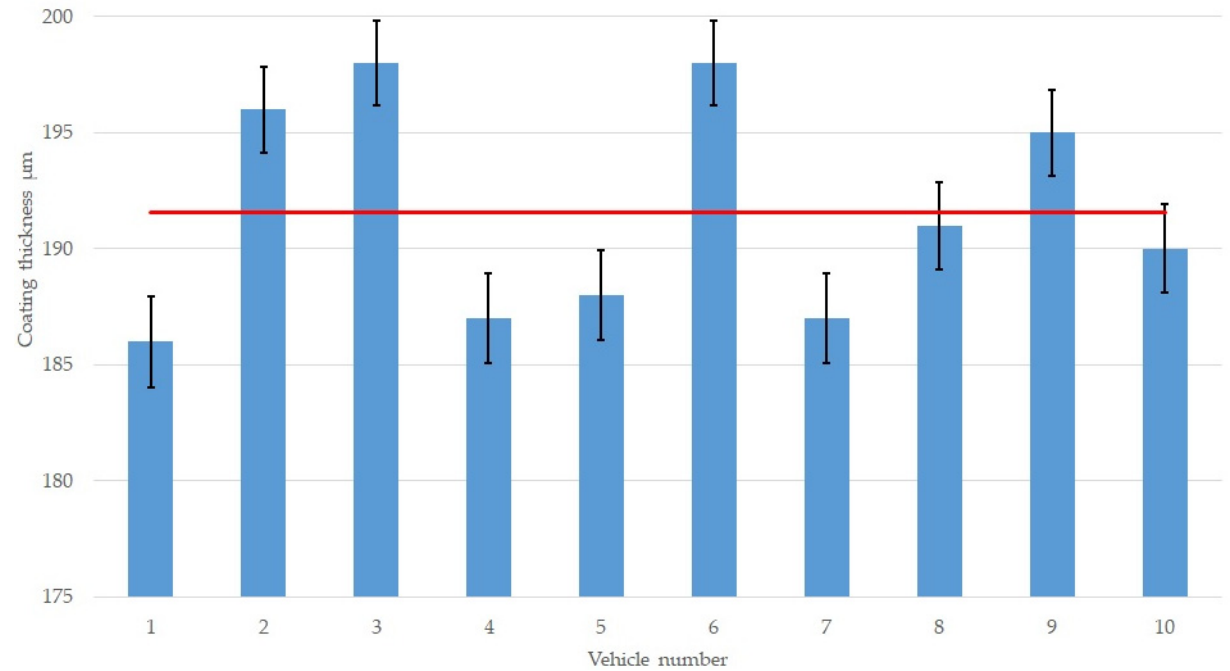

Figure 7. Average coating thickness on the vehicle roof for segment B vehicle (for all 10 vehicles), by the red line, the mean value from 10 vehicles is added.

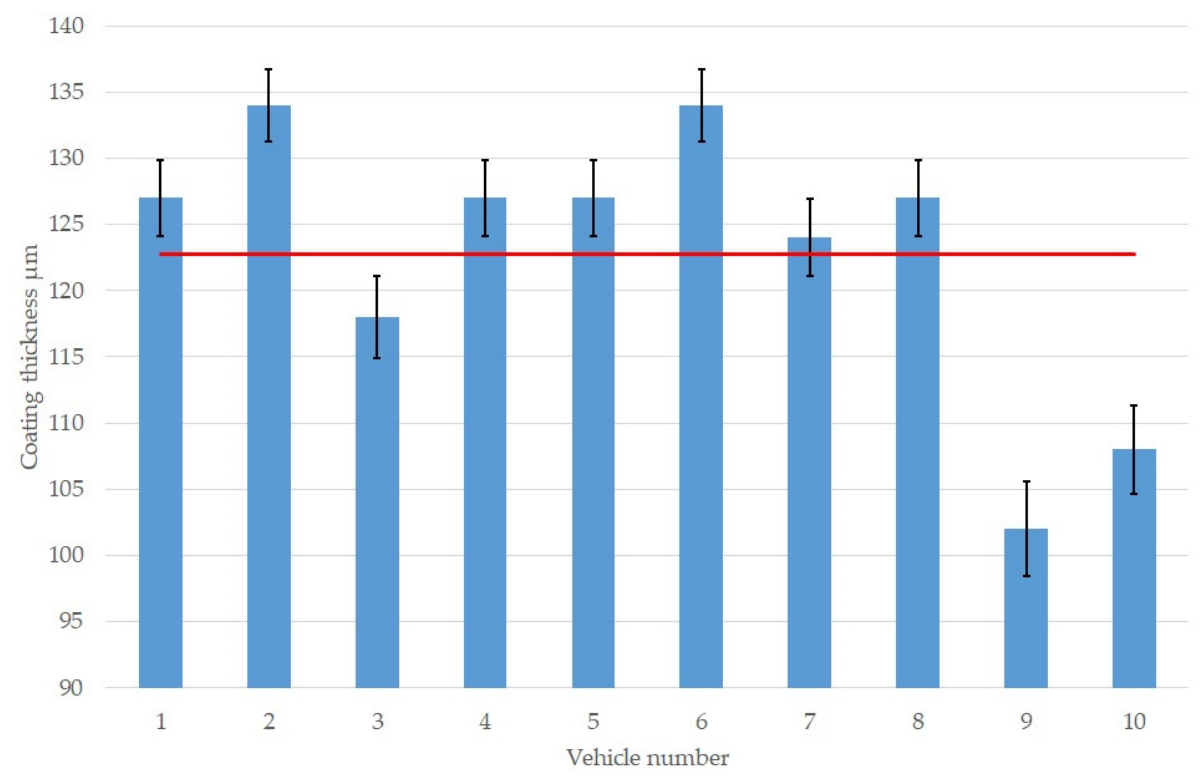

Figure 8. Average coating thickness on the vehicle rear left fender for delivery vehicle (for all 10 vehicles), by the red line, the mean value from 10 vehicles is added.

It was also noticed that the average standard deviation for all measurements is much greater in the case of the commercial vehicle- $9.1 \mu \mathrm{m}$, compared to the segment B vehicle $-2.8 \mu \mathrm{m}$. This may be due to a lower quality criterion for the application of coatings in commercial (delivery) vehicles, affecting price competitiveness. In the case of passenger vehicles, the aesthetic aspect of the vehicle is more important to the user. Therefore, manufacturers pay more attention to the quality of applied coatings. However, the average median difference between the thickness of the varnish layer of the B segment vehicle and the delivery vehicle is small and amounts to $6 \%$. The test results confirmed that all analyzed vehicles had original paint applied by the manufacturer. The obtained test results are consistent with previous studies available in the literature $[5,36,43,44]$, in which the average thickness of the varnish coat of the new vehicle was in the range of 90-145 $\mu \mathrm{m}$.

The differences in the mean thickness value of the varnish coating for individual elements of the B segment and the delivery vehicle are small and amount to about $10 \mu \mathrm{m}$. 
The tested vehicles are not vehicles of one manufacturer. Therefore, differences in thickness may be due to the varnishing technology. In addition, different types of varnish were used, which also affects the thickness of the coating. In addition, delivery vehicles are more exposed to damage to the paint coating, due to their intended use. For this reason, the manufacturer was able to apply a slightly greater thickness of the varnish coat.

Higher value of the coating gloss was found for vehicles tested in the factory (delivery vehicle) compared to vehicles in the car showroom (segment $B$ ). The average gloss values for selected elements of vehicle bodies are shown in Figures 9 and 10.

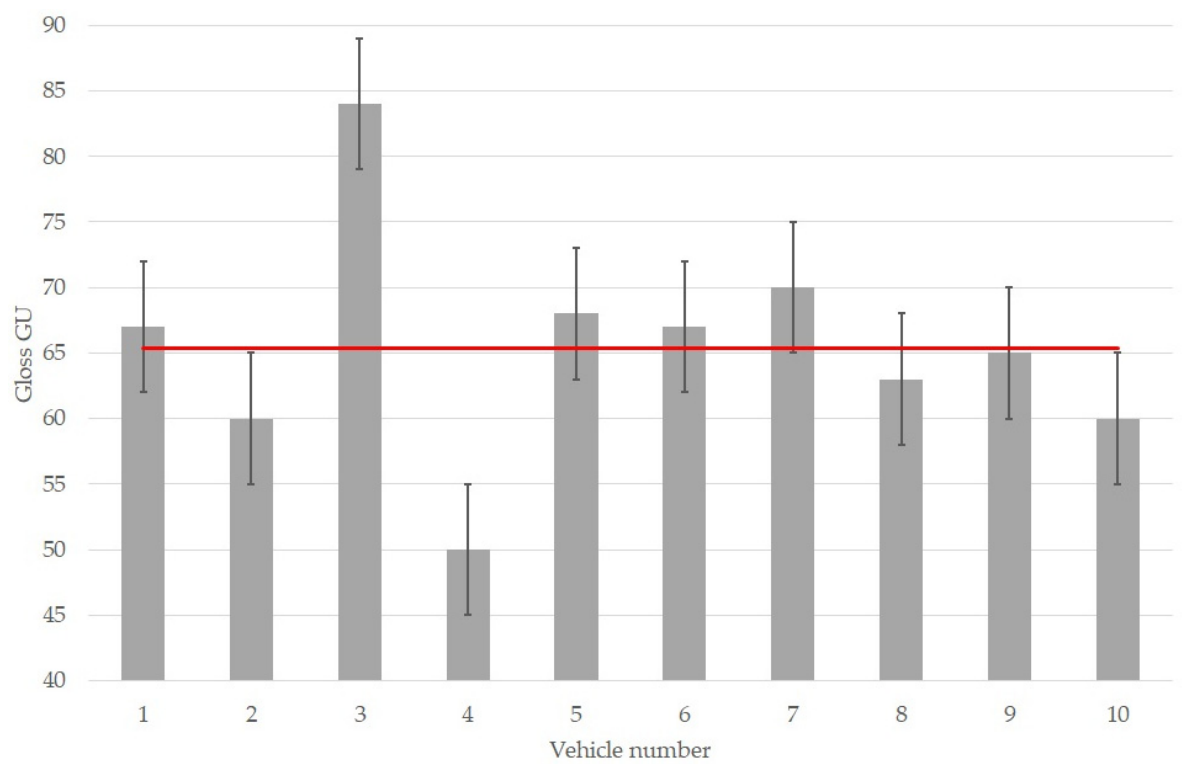

Figure 9. Average coating gloss values on the vehicle rear right fender for segment B vehicle (for all 10 vehicles), by the blue line, the mean value from 10 vehicles is added.

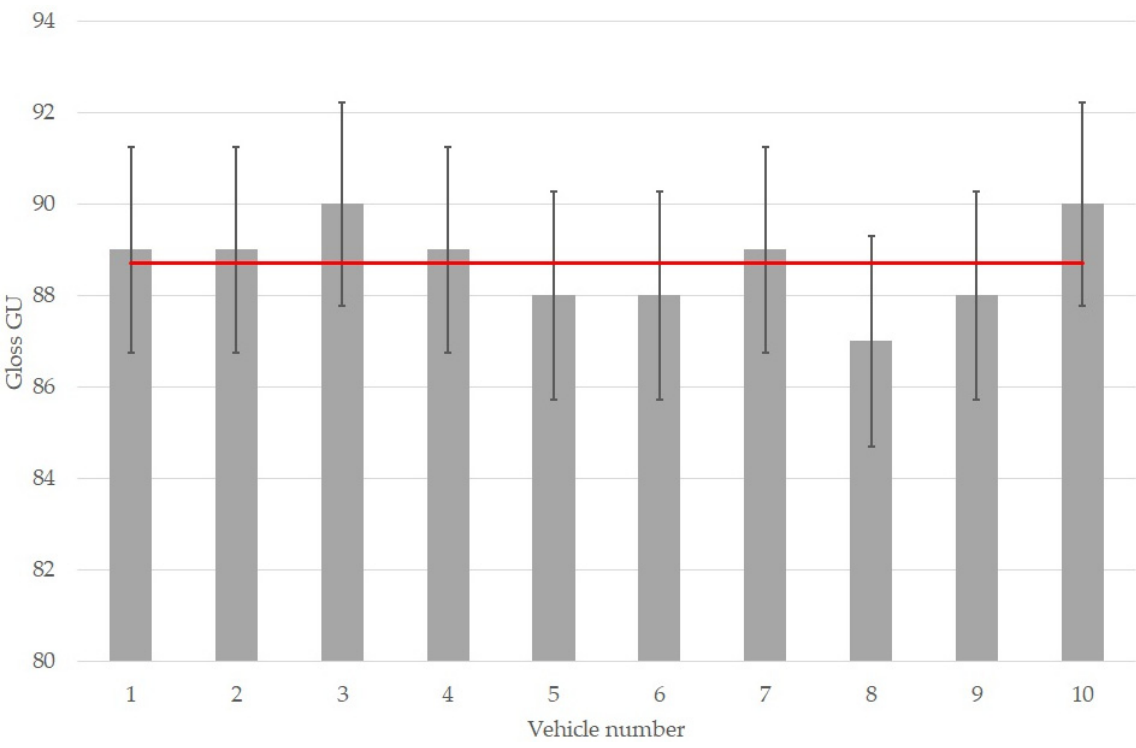

Figure 10. Average coating gloss values on the vehicle front left fender for delivery vehicle (for all 10 vehicles), by the blue line, the mean value from 10 vehicles is added.

The value of the average gloss for the entire vehicle is $88.8 \mathrm{GU}$ for a commercial vehicle and $67.7 \mathrm{GU}$ for a B segment vehicle (test in $20^{\circ}$ ). In the case of the B segment vehicle, there was a clearly higher mean standard deviation of the gloss value, which is $5.6 \mathrm{GU}$ than for a commercial vehicle $(0.49 \mathrm{GU})$. The lowest gloss value for B-segment vehicles is $46 \mathrm{GU}$ (rear left door), the maximum value is $84 \mathrm{GU}$. For a commercial vehicle in which the gloss value 
has been measured on the factory, the minimum value is $87 \mathrm{GU}$ and the maximum value is 90 GU. The obtained results may indicate that the paint coating in segment B vehicles was damaged or contaminated during the transport of the vehicle from the factory to the seller and was not thoroughly washed by service personnel. In the case of the tested vehicles, the distance between the factory and the service point is approximately $2500 \mathrm{~km}$. During transport, the vehicle is exposed to contamination that can generate micro-scratches on the body. Vehicles classified to the premium brands, often on their way from the factory to the showroom, are placed in sealed containers or have a varnish coat covered with a cover, which reduces the possibility of contamination or damage.

Gloss reduction and a relatively high deviation of its value may also indicate a relatively low quality of the varnish of new and renovation coating. Some owners of new vehicles, immediately after leaving the showroom, decide to apply a protective layer to the paint, i.e., a ceramic layer. This is also due to the relatively low cost of applying a protective layer to the vehicle.

The thickness of the renovation coatings is approximately $10 \%$ higher than coatings applied in the factory (except for samples from series 4 and 5). However, it should be noted that during the preparation of the samples, the old varnish was removed. The destructive effect of the sandpaper also damaged the zinc layer, which could be important for the adhesion of the coating to the substrate. In the case of renovation varnishing without completely removing the factory layer, the varnish thickness is much higher and amounts to approximately $240-270 \mu \mathrm{m}$. This result is consistent with the thickness of the varnish coatings given in the literature [1,43]. For the first three series of samples, the gloss values are similar to the results of the measurements on the new coating. Any defects in the coating which are visible on the surface will result in a significant reduction in gloss. The remaining hardness and adhesion tests, complement the previous tests. Nevertheless, in industrial practice, this type of test is not performed due to damage to the coating. The adhesion tests revealed the fact that preparation of the surface even in accordance with the manufacturer's instructions does not ensure good adhesion and the coating may detach from the substrate during operation.

\section{Varnish Coating Assessing Quality Procedure}

The implementation of high-quality renovation coatings requires, compliance with the procedures developed by the manufacturer of the varnish system (varnish products). Nevertheless, in the conditions of authorized car service centers, it is necessary to inspect the car body after repair process. Vehicle users expect the renovation coating quality to be as close as possible to the coating applied at the factory. Therefore, the authors of this article propose some guidelines (the procedure) related to the process of inspection of renovation coatings, which are presented in the form of an evaluation algorithm in Figure 11. The algorithm has been divided into two stages. The first concerns measurements of properties such as thickness and gloss, which can be nondestructively determined after each repair and related to the reference values provided in the article or to measurements made on the vehicle parts that have not been repaired. Additionally, the algorithm is supplemented with destructive tests, which can be used when a new varnish is implemented to the workshop or in the process of improving the technology of repairing varnish coatings. 


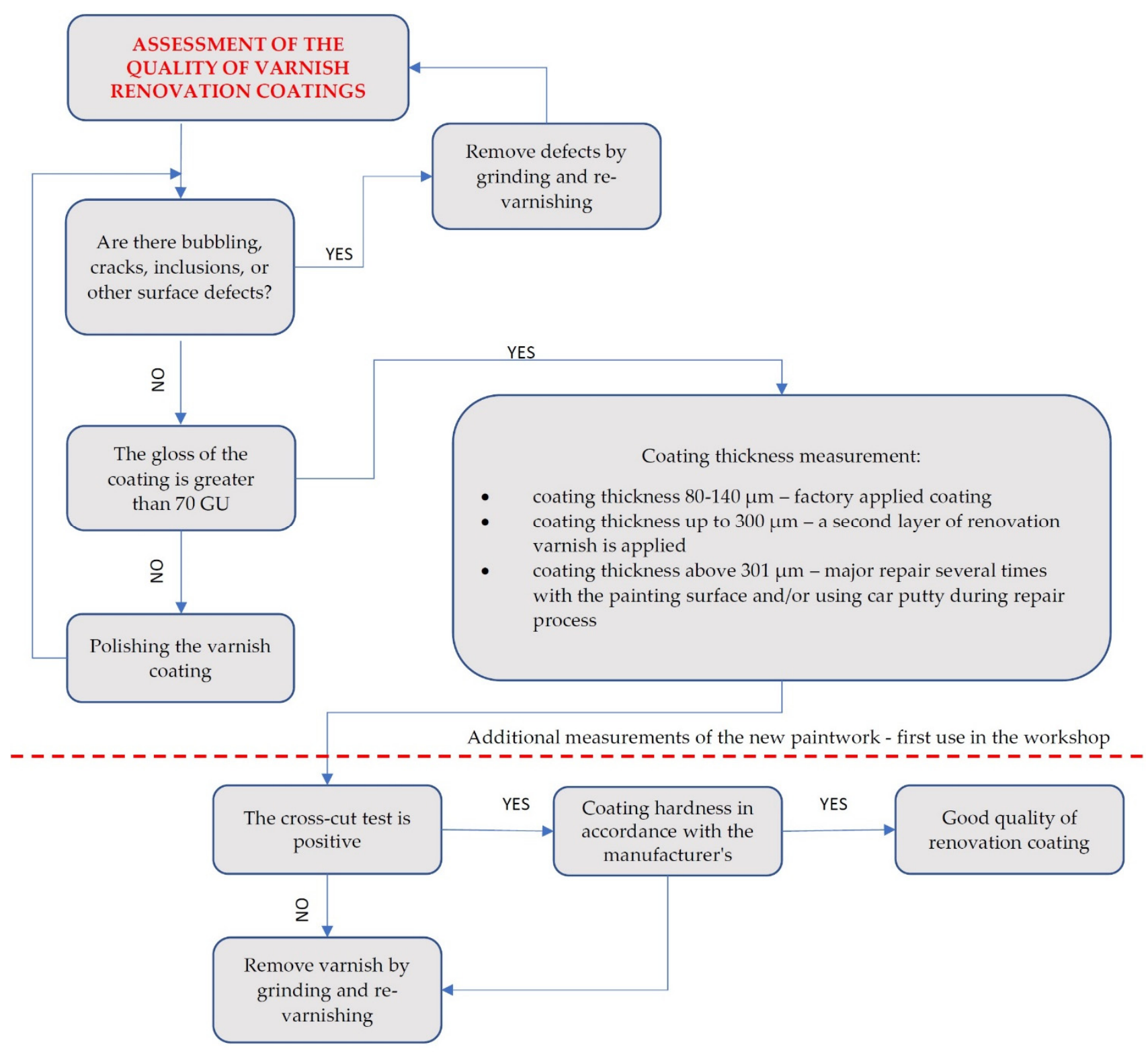

Figure 11. Algorithm for the quality assessment of renovation varnish coatings.

\section{Conclusions}

The properties of automotive renovation coatings such as thickness, gloss, adhesion and hardness during repair should correspond to the current state of the factory coatings. During the process of applying automotive renovation coatings, the guidelines of the manufacturers of materials and devices for applying and hardening these coatings should be followed, as well as the use of technology resulting from the competences of the car painter.

Non-compliance with the guidelines of manufacturers of materials and tools for applying coatings and the specific technology of such application, taking into account the experience of the car painter leads to defects in renovation coatings. Therefore it is difficult to assess the current properties of these coatings and quality control of the correct coating application process.

The developed procedure for verifying the compliance of the quality of the renovation coating with the factory coating and its current condition in terms of its most important properties allows for the assessment of these properties both before and after the application of the automotive renovation coating and during the coating renovation process. The 
average thickness of the coating applied to the body at the factory, determined on the basis of measurements, does not exceed approximately $140 \mu \mathrm{m}$. Therefore, repair coats workshops should produce varnish coats of similar thickness. In the case of varnishing with the second varnish layer, this thickness should not exceed $300 \mu \mathrm{m}$. For the measurement of the gloss of coatings, it is important to verify organoleptically the occurrence of defects (bubbles, flake and cracks), which reduce the value of this parameter. No special equipment or methods are needed for this. Disclosed defects in the paintwork must be removed before measuring the gloss in accordance with the paint manufacturer's instructions. Values in the range of 60-88 GU were obtained for new vehicles, therefore it was assumed that the average gloss value when measured at an angle of $20^{\circ}$ should be higher than $70 \mathrm{GU}$. Other methods of testing hardness and adhesion were introduced in the article in order to estimate the impact of changing the varnishing technology on the durability of the renovation varnish. Unfortunately, any deviations in the varnishing technology (recommended by the varnish manufacturer) significantly reduce the quality of the renovation coating.

The directions of further research on the properties of varnish coatings will include the tests of varnishes applied to aluminum and plastic substrates. It is also important to develop methods of testing the adhesion of varnish coatings, which will not interfere with the structure of the coating. Therefore, the authors plan to use the ultrasonic method to assess the adhesion of thin paint coatings applied to steel and aluminum substrates.

Author Contributions: Conceptualization, D.U. and J.K.; methodology, D.U., W.S. and M.J.; software, P.C. and J.K.; validation, D.U., P.C. and J.K.; formal analysis, D.U.; investigation, D.U., J.K. and P.C.; resources, D.U.; data curation, D.U.; writing—original draft preparation, D.U., M.J., P.C. and W.S.; writing-review and editing, D.U., J.K. and M.J.; visualization, D.U. and J.K.; supervision, D.U. and M.J.; project administration, J.K. and W.S.; funding acquisition, D.U. All authors have read and agreed to the published version of the manuscript.

Funding: This research was funded by Poznan University of Technology, Grant No. 0414/SBAD/3583 and $0414 / \mathrm{SBAD} / 3612$.

Institutional Review Board Statement: Not applicable.

Informed Consent Statement: Not applicable.

Data Availability Statement: The data presented in this study are available on request from the corresponding author.

Conflicts of Interest: The authors declare no conflict of interest.

\section{References}

1. Fettis, G. Automotive Paints and Coatings; Wiley-VCH: Weinheim, Germany, 1995.

2. Akafuah, N.K. Automotive paint spray characterization and visualization. In Automotive Painting Technology; Toda, K., Salazar, A., Saito, K., Eds.; Springer: Dordrecht, The Netherlands, 2013.

3. Yong-Qiu, L.; Xiao-Feng, L. Design of car coating system based on PLC. In Proceedings of the 2014 IEEE Workshop on Advanced Research and Technology in Industry Applications (WARTIA), Ottawa, ON, Canada, 29-30 September 2014.

4. Kotnarowska, D. The influence of battery acid on the destruction of acrylic coatings of car bodies. Coatings 2021, 11, 967. [CrossRef]

5. Akafuah, N.K.; Poozesh, S.; Salaimeh, A.; Patrick, G.; Lawler, K.; Saito, K. Evolution of the automotive body coating process-A review. Coatings 2016, 6, 24. [CrossRef]

6. Buzzini, P.; Stoecklein, W. Forensic Sciences: Paints, Varnishes, and Lacquers. Encyclopedia of Analytical Science, 2nd ed.; Elsevier: Amsterdam, The Netherlands, 2005.

7. Idumah, C.I.; Obele, C.M.; Obumneme, E.E.; Hassan, A. Recently emerging nanotechnological advancements in polymer nanocomposite coatings for anti-corrosion, anti-fouling and self-healing. Surf. Interfaces 2020, 21, 100734. [CrossRef]

8. Van Schaik, M.; Dane, C.; Berkhout, B. MagiZinc-The New High Performance Coating for Steel in the BIW and Closures. In Proceedings of the SAE 2016 World Congress and Exhibition, Detroit, MI, USA, 12-14 April 2016; SAE International: Warrendale, PY, USA, 2016. [CrossRef]

9. Lee, C.W.; Choi, W.S.; Cho, Y.R.; De Cooman, B.C. Surface oxide formation during rapid heating of Zn-coated press hardening steel. ISIJ Int. 2014, 54, 2364-2368. [CrossRef]

10. Czachor-Jadacka, D.; Pilch-Pitera, B. Progress in development of UV curable powder coatings. Prog. Org. Coat. 2021, 158, 106355. [CrossRef] 
11. Schiel, M.; Kreling, S.; Unger, C.; Fischer, F.; Dilger, K. Behavior of adhesively bonded coated steel for automotive applications under impact loads. Int. J. Adhes. Adhes. 2015, 56, 32-40. [CrossRef]

12. Khasanov, I.K.; Rassokha, V.I.; Zolotarev, Y.S. Improvement of the protection technique of paint and varnish coating of the car body while operating. Intellect. Innovations. Investments 2017, 11, 51-54.

13. Mertens, M.L. Multifunctional coatings in the automotive finishing industry. Met. Finish. 1998, 96, 10-14. [CrossRef]

14. Bewilogua, K.; Bräuer, G.; Dietz, A.; Gäbler, J.; Goch, G.; Karpuschewski, B.; Szyszka, B. Surface technology for automotive engineering. CIRP Ann. 2009, 58, 608-627. [CrossRef]

15. Kettler, W.; Richter, G. Investigation on topology of platelet-like effect-pigments in automotive surface-coatings. Prog. Org. Coat. 1997, 31, 297-306. [CrossRef]

16. Jiang, B.; Chen, A.; Gu, J.; Fan, J.; Liu, Y.; Wang, P.; Li, H.; Sun, H.; Yang, J.; Wang, X. Corrosion resistance enhancement of magnesium alloy by $\mathrm{N}$-doped graphene quantum dots and polymethyltrimethoxysilane composite coating. Carbon 2019, 157, 537-548. [CrossRef]

17. Fan, J.; Fu, T. Composite design of thin hard $\mathrm{AlNi}_{3}$ coating on soft stainless steel for making the improved impact resistance. Surf. Coat. Technol. 2019, 368, 1-7. [CrossRef]

18. Fan, J.; Fu, T. Toughened austenitic stainless steel by surface severe plastic deformation. Mater. Sci. Eng. A 2012, 552, 359-363. [CrossRef]

19. Koca, F. Evaluation of Factors Affecting Repaint Adhesion of Automotive Coating Systems. Master's Thesis, Department of Chemistry and Chemical Engineering, Chalmers University of Technology, Gothenburg, Sweden, 2021.

20. Croll, S. Surface roughness profile and its effect on coating adhesion and corrosion protection: A review. Prog. Org. Coat. 2020, 148, 105847. [CrossRef]

21. Streitberger, H.J.; Dossel, K.F. Automotive Paints and Coatings; WILEY-VCH Verlag GmbH \& Co. KGaA: Weinheim, Germany, 2008; ISBN 978-3-527-30971-9.

22. Kuczmaszewski, J. Fundamentals of Metal-Metal Adhesive Joint Design; Lublin University of Technology: Lublin, Poland, 2006.

23. Lieng-Huang, L. Fundamentals of Adhesion. Xerox Corporation; Springer Science+Media LCC: Webster, NY, USA, 1991.

24. Lomax, P. Selecting the right coating thickness measurement probe for the job: Practical considerations, as well as tolerance requirements, determine appropriateness of measuring device. Met. Finish. 2006, 104, 14-19. [CrossRef]

25. Daikos, O.; Heymann, K.; Scherzer, T. Monitoring of thickness and conversion of thick pigmented UV-cured coatings by NIR hyperspectral imaging. Prog. Org. Coat. 2018, 125, 8-14. [CrossRef]

26. Rassokha, V.I.; Khasanov, I.K. Nondestructive control method of technical condition of paint and varnish coating with use of the spectrophotometer. News Tula State Univ. 2015, 6, 178-183.

27. Golovanov, Y.V.; Khasanov, I.K. Thermovision Control Method of the Technical Condition of the Car Body; Bulletin of Orenburg State University: Orenburg, Russia, 2014; Volume 10, pp. 54-59.

28. Bondarenko, Y.V.; Golovanov, Y.V.; Khasanov, I.K. Nondestructive control of the paint and varnish coating thickness of the car body. In Proceedings of the 4th International Scientific and Practical Internet Conference: Relevant Issues of Innovative Development of Transport Complex (Oryol: “Gosuniversitet-UNPK”), Irkutsk, Russia, 27 May-1 June 2014; pp. $24-28$.

29. Khasanov, I.K.; Golovanov, Y.V. Nondestructive control of the technical condition of the car body with the use of a vor-tex-current method. In Proceedings of the International Scientific and Technical Conference: Transport and Transport and Technological Systems (Tumen:.TumSOGU) Online, Algrave, Portugal, 28-30 May 2014; pp. 259-263.

30. Molina, J.; Solanes, E.; Arnal, L.; Tornero, J. On the detection of defects on specular car body surfaces. Robot. Comput. Manuf. 2017, 48, 263-278. [CrossRef]

31. Medina José, M.; Díaz José, A. Fluctuation scaling of color variability in automotive metallic add-on parts. Prog. Org. Coat. 2017, 104, 118-124. [CrossRef]

32. Lane Stephen, G. Real-Time weathering as a test for evaluating paint coatings. Met. Finish. 2000, 98, 546-558. [CrossRef]

33. Schönberger, A.; Virtanen, S.; Giese, V.; Spießberger, C.; Schröttner, H.; Rattenberger, J.; Wagner, J. Non-destructive evaluation of stone-impact damages using Pulsed Phase Thermography. Corros. Sci. 2011, 56, 168-175. [CrossRef]

34. Khasanov, I.; Rassokha, V.; Kabanova, O. The study on the factors influencing the quality of paint and varnish coating when repairing the car body. IOP Conf. Ser. Mater. Sci. Eng. 2019, 632, 012073. [CrossRef]

35. Suleimanov, I.F.; Nazmutdinov, A.K.; Khasanov, I.K.; Rassokha, V.I.; Filippov, A.A. Actions research of technical condition of paint and varnish coating of the car body before taking repair. Int. J. Mech. Prod. Eng. Res. Dev. 2018, 8, 465-471.

36. Losavio, S.K. Investigation of the Paint and Varnish Coating of the Car Body. "ABS Auto", Electronic Source. Available online: https: / / expertauto.pro/car-body/issleduem-lakokrasochnoe-pokritie-kuzova (accessed on 1 September 2021).

37. Gómez, O.; Perales, E.; Chorro, E.; Burgos, F.J.; Viqueira, V.; Vilaseca, M.; Martínez-Verdú, F.M.; Pujol, J. Visual and instrumental assessments of color differences in automotive coatings. Color Res. Appl. 2015, 41, 384-391. [CrossRef]

38. PC-Leptoskop 2050, Coating Thickness Measurement on PC Basis, Karl Deutsch, Germany, Device Flyer. Available online: http:/ / www.ndttechnologies.com/Brochures/Coating\%20Thickness\%20Gauge/LEPTOSKOP_2050\%20Catalogue.pdf (accessed on 1 September 2021).

39. PN-EN ISO 2409:2021-03 standard. Paints and Varnishes-Cross Cut Test; International Organization for Standardization: Geneva, Switzerland, 2021. 
40. PN-EN ISO 15184 Standard. Paints and Varnishes-Delamination of Film Hardness by Pencil Test; International Organization for Standardization: Geneva, Switzerland, 2020.

41. PN-EN ISO 2813:2014-11 Standard. Paints and Varnishes-Determination of Gloss Value at $20^{\circ}, 60^{\circ}$ and $85^{\circ}$; International Organization for Standardization: Geneva, Switzerland, 2014.

42. Ulbrich, D.; Jósko, M.; Mańczak, R. An Investigation of degradation of bond between coating and substrate. J. Res. Appl. Agric. Eng. 2011, 56, 142-146.

43. Stefański, Ł.; Jósko, M. Badanie grubości powłok lakierniczych leptoskopem kd-2050. J. Res. Appl. Agric. Eng. 2011, 56, 144-150.

44. Stefański, Ł.; Jósko, M.; Ulbrich, D.; Kowalczyk, J. Wysoka jakość powłok. Badanie rozkładu grubości powłok lakierniczych elementu karoserii pojazdu samochodowego. Lakiernictwo Przemysłowe 2013, 6, 52-53. 